\title{
Syntheses and Reactions of Uniform Size Poly(dimethylsiloxane) with Various Reactive End Groups
}

\author{
Hideki KaZAma, Yasuyuki TeZUKA, ${ }^{*}$ and Kiyokazu IMAI* \\ Department of Materials Science and Technology, Technological University of Nagaoka, \\ Kamitomioka, Nagaoka, Niigata 940-21, Japan
}

(Received March 26, 1987)

\begin{abstract}
The reaction of monofunctional living poly(dimethylsiloxane), poly(DMS), with dimethylchlorosilane (2), followed by the hydrosilation of the polymer end $\mathrm{SiH}$ group with allyl alcohol was performed. The hydroxyl end group of poly(DMS) (4) thus obtained was subsequently converted to the tosylate ester group through treatment with tosyl chloride in the presence of 4dimethylaminopyridine (DMAP). The tosylate ester end group of poly(DMS) (5) was found to initiate the cationic ring opening polymerization of 2-methyl-2-oxazoline (OXZ) to produce the poly(DMS)/poly(OXZ) block copolymer (7).

KEY WORDS Poly(dimethylsiloxane) / Reactive Oligomer / Block Copolymer / Poly(oxazoline) / Hydrosilation / Reactive End Group / Narrow Molecular Weight Distribution /
\end{abstract}

Uniform size oligomers, i.e., those of the desired molecular weight with narrow molecular weight distribution, having reactive end group, are considered to be important as macromolecular building blocks for the synthesis of precisely designed block and graft copolymers. The control of molecular weight distribution as well as average molecular weight is strongly required in order to elucidate the molecular level structure-property relationship of these multiphase polymer materials, since their microphase separation morphology arising from the incompatibility of polymer segment components is markedly influenced by these parameters. ${ }^{1}$

The block and graft copolymers consisting of poly(dimethylsiloxane), poly(DMS), as one of the segment components have been attracting growing interest due to their unique properties both in bulk and at surface, ${ }^{2}$ and an increasing number of attempts have been car- ried out to develop a convenient and reliable reaction system to provide the poly(DMS) oligomer with various reactive end groups for the synthesis of desired multiphase polymers containing the well-defined poly(DMS) segment. ${ }^{3}$ Nevertheless, surprisingly little attention has been paid to the control of the molecular weight distribution in the synthesis of poly(DMS) oligomers with reactive end groups.

This paper describes the results on the syntheses and reactions of novel uniform size poly(DMS)s with various reactive end groups by utilizing the unique reactivity of silicone compounds as well as by combining available synthetic techniques in organic chemistry. The selective and quantitative derivatization of the end standing group of the polymer is required due to the inherent difficulty in the separation of the polymer side product in this particular reaction system. Thus, the following reaction

\footnotetext{
* To whom correspondence should be addressed.
} 


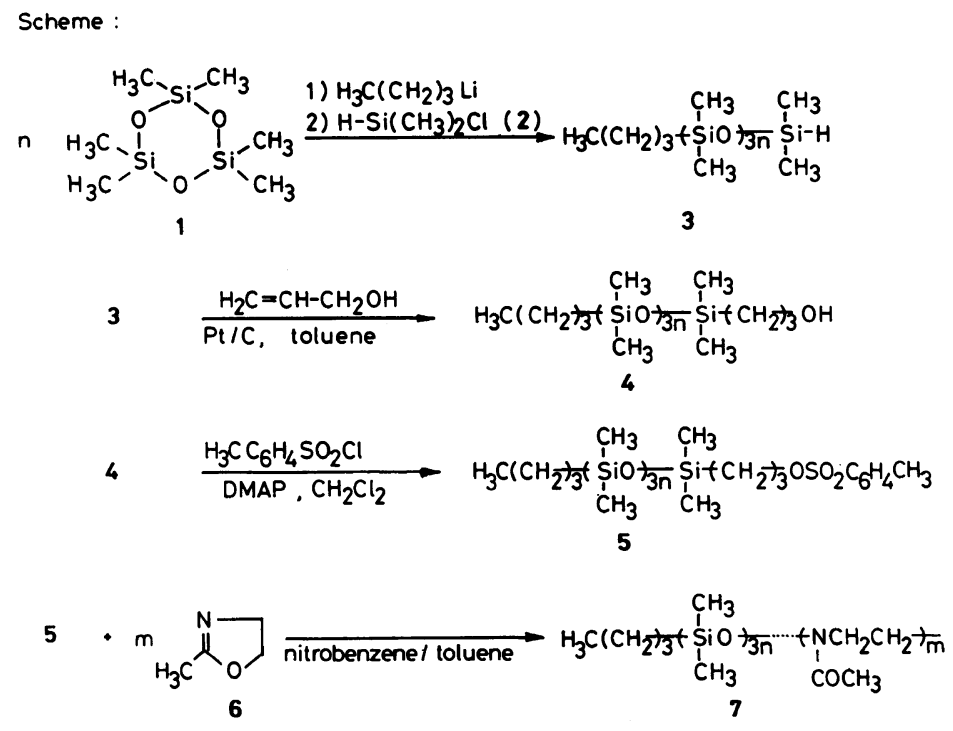

processes were adopted as shown in the scheme,

1) Poly(DMS) with $\mathrm{SiH}$ end group (3) was prepared through the reaction of the living poly(DMS) with dimethylchlorosilane (2).

2) The hydrosilation reaction of the polymer end $\mathrm{SiH}$ function (3) with allyl alcohol in the presence of platinum catalyst provided the hydroxypropyl end poly(DMS) (4).

(3) The hydroxyl end group of poly(DMS) (4) was then converted to the tosylate ester group by the reaction with tosyl chlorode in the presence of 4-dimethylaminopyridine (DMAP).

4) The tosylate end poly(DMS) oligomer (5) was used as a macromolecular initiator to produce poly(DMS)/poly(oxazoline) block copolymer (7).

\section{EXPERIMENTAL}

\section{Reagents}

Hexamethylcyclotrisiloxane $\left(\mathrm{D}_{3}\right)$ (1) and dimethylchlorosilane (2) (both from Toshiba Silicone Co.) were purified by the distillation over $\mathrm{CaH}_{2}$. n-Butyllithium (Nakarai Chemicals Ltd., 1.4 M in $n$-hexane) was used after titration according to Gilmam and Haubein. ${ }^{4}$
Allyl alcohol was used after distillation. $\mathrm{Pt} / \mathrm{C}$ (5\%-Pt, Japan Engelhard Co.) was used as received. Tosyl chloride was recrystallized from diethyl ether. 4-Dimethylaminopyridine, DMAP, was twice recrystallized from ethyl acetate. 2-Methyl-2-oxazoline (OXZ) was purified by the distillation over $\mathrm{CaH}_{2}$. THF, benzene, toluene and $n$-hexane were distilled over sodium wire. Other reagents were purified by the usual method.

Synthesis of the Uniform Size Poly(DMS) with $\mathrm{SiH}$ End Group (3)

A living poly(DMS) was prepared by the polymerization of $\mathrm{D}_{3}$ (1) with the required amount of butyllithium in THF as reported before. $^{5}$ Excess dimethylchlorosilane (2) (molar ratio of $(2) /$ butyllithium $=5$ ) was then added and stirred for $2 \mathrm{~h}$. After the solvent and (2) were evacuated under reduced pressure, the product was subjected to filtration in order to remove lithium chloride. The reaction product was finally purified by freezedrying from benzene solution.

Synthesis of the Uniform Size Poly(DMS) with Hydroxypropyl End Group (4)

Twenty grams of poly(DMS) with $\mathrm{SiH}$ end 
group (3) were dissolved in $80 \mathrm{ml}$ of dry toluene in a $200 \mathrm{ml}$ flask and $0.34 \mathrm{~g}(0.001$ mol1 $1^{-1}$ ) of $\mathrm{Pt} / \mathrm{C}$ was introduced under nitrogen. There upon a large excess of allyl alcohol (molar ratio of 3/allyl alcohol $=1 / 50$ $1 / 150$ ) was added by a syringe and stirred for a prescribed period in a thermostated bath. The reaction product was isolated and purified by the successive precipitation into methanol after the filtration of $\mathrm{Pt} / \mathrm{C}$, and finally freezedried from benzene solution.

Synthesis of the Uniform Size Poly(DMS) with Tosylate End Group (5)

Onto a dichloromethane solution of poly(DMS) with the hydroxypropyl end group (4), a weighed amount of tosyl chloride, DMAP and, in some cases, triethylamine were added rapidly under stirring and the reaction solution was continued with stirring for $22 \mathrm{~h}$ at $20^{\circ} \mathrm{C}$. The reaction product was extracted with $60 \mathrm{ml}$ of dry $n$-hexane and was purified by the repreated precipitation into methanol, and finally freeze-dried from benzene solution.

\section{Reaction of the Uniform Size Poly(DMS) with Tosylate End Group (5)}

A weighed amount of $\mathrm{OXZ}$ was mixed with the poly(DMS) with tosylate end group (5) in toluene/nitrobenzene solution. The reaction mixture was then heated at 80 to $100^{\circ} \mathrm{C}$ for 24 to $48 \mathrm{~h}$. A white powdery precipitate formed during the reaction. The reaction mixture was poured into diethyl ether and the precipitated product was recovered and washed with diethyl ether more than five times and dried in vacuo at room temperature.

\section{Measurements}

$270 \mathrm{MHz}{ }^{1} \mathrm{H}$ NMR spectra were recorded by JEOL JNM-GX270 apparatus. The chemical shift was calibrated using the $\mathrm{CHCl}_{3}$ $(7.30 \mathrm{ppm})$ signal as internal standard. IR spectra were taken on Hitachi 260-10 Infrared Spectrophotometer. GPC measurements were carried out using a Toyo Soda Model 803C
High Speed Liquid Chlomatograph equipped with a TSK G3000 HXL as a column and chloroform or THF as eluent. VPO measurement was carried out in toluene solution with a CORONA model 114 apparatus. TLC measurements were carried out using an aluminum oxide plate (Merck kieselgel $60 \mathrm{~F}_{254}$ ) of $2.5 \mathrm{~cm}$ width and $10 \mathrm{~cm}$ height with chloroform as a spotting solvent and with iodine as the indicator.

\section{RESULTS AND DISCUSSION}

\section{Synthesis of the Uniform Size Poly(DMS) with SiH End Group (3)}

Hexamethylcyclotrisiloxane $\left(D_{3}\right) \quad(1)$ is known to polymerize in a living character with lithium initiators like butyllithium or lithium silanolate. ${ }^{6}$ The modification of the living $\mathrm{SiOLi}$ end group has been recently attempt so as to introduce the polymeriable group, namely styryl, $^{7}$ methacryl, ${ }^{7,8}$ and vinyl silanyl ${ }^{5}$ group, as "macromonomer" for the synthesis of precisely characterized graft copolymers.

In the present study, the silane $(\mathrm{SiH})$ group was introduced as the end function of poly(DMS) in the first step, since the $\mathrm{SiH}$ group can undergo the hydrosilation reaction to add to unsaturated vinyl or allyl compounds, $, 9,10$ to allow further derivatization reaction. Thus, the reaction of dimethylchlorosilane (2) with a living poly(DMS), prepared by the polymerization of (1) with $n$-butyllithium in THF solution, was carried out. The reaction product was subjected to $270 \mathrm{MHz}$ ${ }^{1} \mathrm{H}$ NMR spectroscopic analysis; this was found to be a versatile and reliable technique to observe the reaction occurring at the end group of polymers with the molecular weight up to ten thousands.

Figure 1 shows the $270 \mathrm{MHz}{ }^{1} \mathrm{H}$ NMR spectrum of the thus obtained poly(DMS) with $\mathrm{SiH}$ as the single end group. The signals due to both end groups, namely the butyl group derived from the initiator at $0.60,0.95$, and 
d)

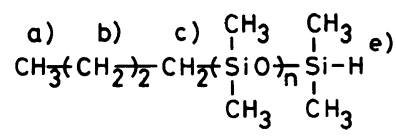

d)

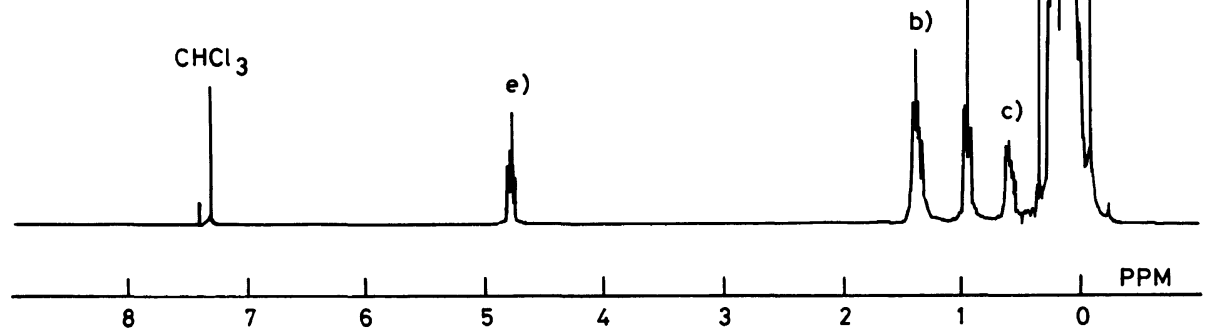

Figure 1. $270 \mathrm{MHz}^{1} \mathrm{H}$ NMR spectrum of poly(DMS) with silane end group (3) (No. 2 in Table I) in $\mathrm{CDCl}_{3}$.

Table I. Results of the synthesis of poly(DMS) with silane end group (3)

\begin{tabular}{|c|c|c|c|c|c|c|}
\hline \multirow{2}{*}{ No. } & \multirow{2}{*}{$\frac{1}{\mathrm{mol1}^{-1}}$} & \multirow{2}{*}{$\frac{\mathrm{C}_{4} \mathrm{H}_{9} \mathrm{Li}}{\mathrm{mol1}^{-1}}$} & \multirow{2}{*}{$\frac{2}{\mathrm{moll}^{-1}}$} & \multirow{2}{*}{$\begin{array}{l}\text { Yield } \\
\text { in \% }\end{array}$} & \multicolumn{2}{|c|}{$\bar{M}_{n}$} \\
\hline & & & & & Calcd $^{\mathrm{b}}$ & Found $^{c}$ \\
\hline 1 & 2.25 & 0.225 & 1.125 & 97.0 & 2300 & 2200 \\
\hline 2 & 2.25 & 0.135 & 0.675 & 93.5 & 3600 & 3600 \\
\hline 3 & 2.25 & 0.070 & 0.350 & 93.0 & 6800 & 6800 \\
\hline
\end{tabular}

a In THF (80 ml); $t=3 \mathrm{~h} ; T=20^{\circ} \mathrm{C}$.

b $\bar{M}_{n}=\frac{1}{\mathrm{C}_{4} \mathrm{H}_{9} \mathrm{Li}} \cdot \frac{\text { Yield }}{100} \cdot 222+116$ (molecular weight of $\left(\mathrm{CH}_{2}\right)_{3} \mathrm{CH}_{3}$ and $\left.-\mathrm{Si}\left(\mathrm{CH}_{3}\right)_{2} \mathrm{H}\right)$.

c By vapor pressure osmometry.

$1.35 \mathrm{ppm}$ respectively, and the silane group from terminating reagent as a multiplet at 4.77 ppm, were clearly observed aside from the overflowed signal of the poly(DMS) main chain at around $0 \mathrm{ppm}$. The molar ratio between the butyl group from the initiator and the silane group from the termination reagent was found to be unity, indicating that the termination reaction took place quantitatively.

A series of poly(DMS)s with $\mathrm{SiH}$ end group (3), possessing the desired molecular weight with the narrow molecular weight distribution, can be prepared by regulating the initiatormonomer ratio, as summarized in Table $\mathrm{I}$. These poly(DMS) oligomers (3) were obtained in an almost quantitative yield and their poly- 
dispersities $\left(\bar{M}_{w} / \bar{M}_{n}\right)$ were found to be always less than 1.10, which was estimated from GPC analysis by comparison with those of standard polystyrene samples of known $\bar{M}_{w} / \bar{M}_{n}$ value. The observed molecular weight of the thus obtained poly(DMS) oligomer (3) was in good agreement with the calculated one in each case, confirming that the initiation is fast and quantitative in this polymerization system.

It should be noted that the isolation and purification of the present silane end poly(DMS) (3) should be carried out not by the usual technique, namely the precipitation into methanol, but by the evacuation of volatile reagents. The methoxy end poly(DMS) resulted by the usual treatment through the reaction of the silane end group with methanol due to an acidic condition caused by the reaction between dimethylchlorosilane (2) and methanol during the precipitation procedure.
Table II. Results of the synthesis of poly(DMS) with hydroxypropyl end group (4)

\begin{tabular}{|c|c|c|c|c|}
\hline \multirow[t]{2}{*}{ No. } & \multirow[t]{2}{*}{$\bar{M}_{n}$ of $\mathbf{3}$} & \multirow{2}{*}{$\frac{\text { Temp }}{{ }^{\circ} \mathrm{C}}$} & \multirow{2}{*}{$\frac{\text { Time }}{\mathrm{h}}$} & \multirow{2}{*}{$\begin{array}{c}\begin{array}{c}\text { Yield of } \\
\text { hydroxypropyl } \\
\text { end group (4) }\end{array} \\
\mathrm{mol} \%\end{array}$} \\
\hline & & & & \\
\hline A-1 & 2200 & 40 & 6 & 15 \\
\hline A-2 & 2200 & 20 & 8 & 40 \\
\hline A-3 & 2200 & 13 & 10 & 100 \\
\hline B-1 & 3600 & 40 & 6 & 46 \\
\hline B-2 & 3600 & 20 & 12 & 63 \\
\hline B-3 & 3600 & 13 & 15 & 100 \\
\hline C-1 & 6800 & 40 & 6 & 53 \\
\hline $\mathrm{C}-2$ & 6800 & 20 & 12 & 76 \\
\hline C-3 & 6800 & 13 & 20 & 100 \\
\hline
\end{tabular}

a In toluene $(80 \mathrm{ml})$; poly(DMS) with silane end group (3) $(20.0 \mathrm{~g})$, allyl alcohol (26.4 g), Pt/C (0.35 g). d)

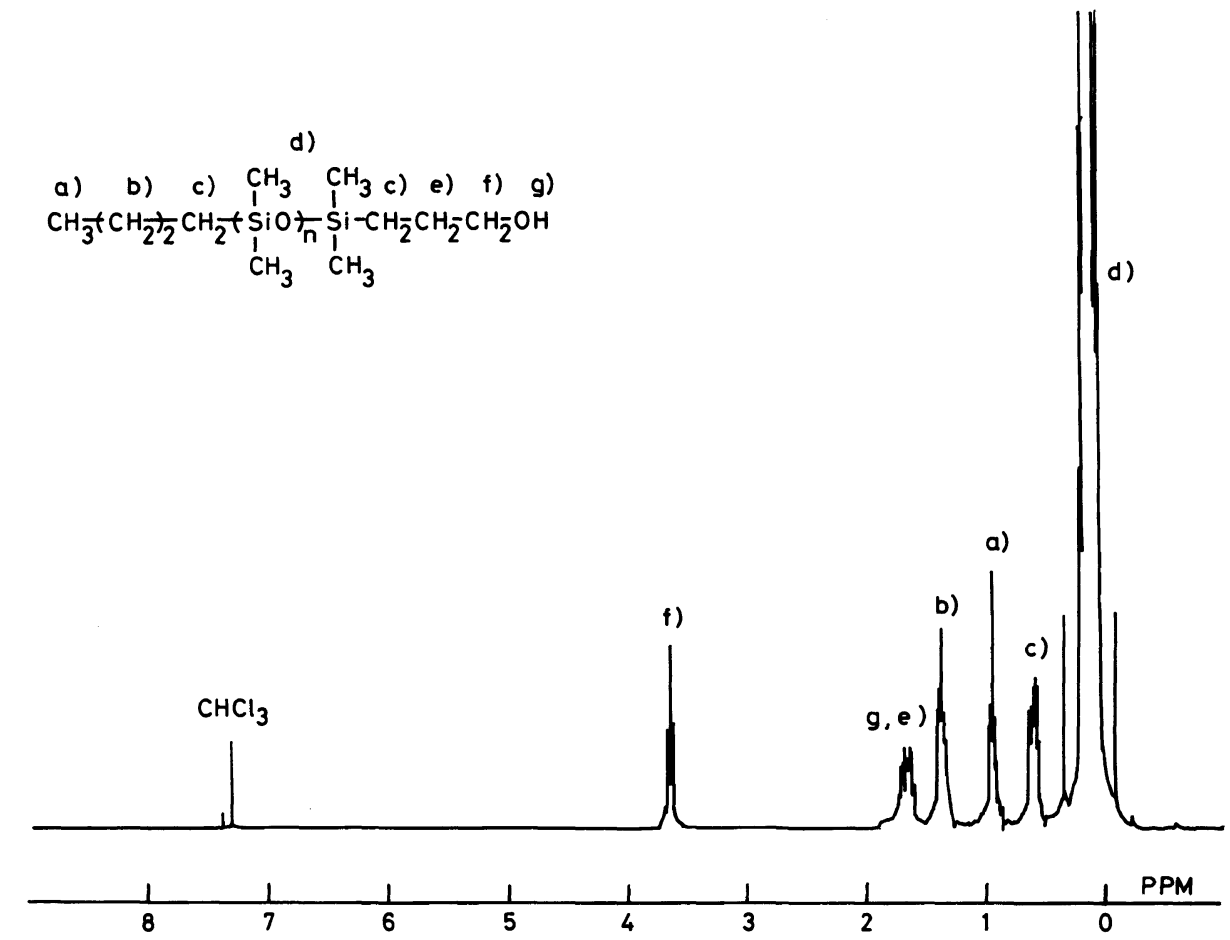

${ }^{b}$ Determined by ${ }^{1} \mathrm{H}$ NMR spectrum.

Figure 2. $270 \mathrm{MHz}{ }^{1} \mathrm{H}$ NMR spectrum of poly(DMS) with hydroxypropyl end group (4) (No. B-3 in Table II) in $\mathrm{CDCl}_{3}$. 
Synthesis of the Uniform Size Poly(DMS) with Hydroxypropyl End Group (4)

The hydrosilation reaction of the obtained poly(DMS) having silane end group (3) with various functional allyl compounds is expected to provide new poly(DMS) oligomers with a variety of reactive end groups.

In the present article, the hydrosilation reaction with allyl alcohol is discussed in detail. The selective and quantitative hydrosilation reaction of the $\mathrm{SiH}$ end group with allyl alcohol was observed to take place at $13^{\circ} \mathrm{C}$, regardless of the molecular weight of poly(DMS) oligomer, as summarized in Table II.

Figure 2 shows $270 \mathrm{MHz}{ }^{1} \mathrm{H}$ NMR spectrum of the reaction product between poly(DMS) with silane end group (3) and allyl alcohol at $13^{\circ} \mathrm{C}$. The signal of the hydroxy methylene group was observed at $3.64 \mathrm{ppm}$ with the complete consumption of the silane signal at $4.77 \mathrm{ppm}$ for the reaction product at $13^{\circ} \mathrm{C}$. The addition reaction was found to proceed in an anti-Markovnikov mode selectively. On the contrary, the higher reaction temperature caused the dehydrogenation reaction between the hydroxy group of allyl alcohol and the $\mathrm{SiH}$ group of the polymer chain end in the presence of platinum catalyst $^{11}$ to form the allyloxy end group, as can be seen by the presence of a considerable amount of protons assignable to the allyloxy group signals at 4.25, 5.20, and $5.98 \mathrm{ppm}$ in ${ }^{1} \mathrm{H}$ NMR.

\section{Synthesis of the Uniform Size Poly(DMS) with} Tosylate End Group (5)

The uniform size poly(DMS) with hydroxy end group (4) was then subjected to the reaction with tosyl chloride. The resulting poly(DMS) with tosylate end group (5) may be utilized as a convenient polymeric initiator for the synthesis of block and graft copolymers of the well defined structure, since the tosylate group is a good leaving group on the attack by various nucleophilic monomers.

The tosylation reaction of the hydroxy end group of poly(DMS) with various molecular weights was found to proceed in a high yield, when a slightly excess of tosyl chloride to hydroxy group was employed in the presence of DMAP, ${ }^{12}$ as summarized in Table III.

The extent of the reaction was evaluated by measuring the appearance of the tosyl group in

Table III. Results of the synthesis of poly(DMS) with tosylate end group (5)

\begin{tabular}{|c|c|c|c|c|c|c|c|}
\hline \multirow{3}{*}{ No. } & \multicolumn{6}{|c|}{ Feed } & \multirow{3}{*}{$\begin{array}{l}\begin{array}{c}\text { Yield of tosylate } \\
\text { end group }(5)^{\mathrm{e}}\end{array} \\
\mathrm{mol} \%\end{array}$} \\
\hline & \multicolumn{2}{|c|}{4} & \multirow{2}{*}{$\frac{\mathrm{TsCl}^{\mathrm{b}}}{\mathrm{mmol}}$} & \multirow{2}{*}{$\frac{\mathrm{NEt}_{3}{ }^{\mathrm{c}}}{\mathrm{mmol}}$} & \multirow{2}{*}{$\frac{\mathrm{DMAP}^{\mathbf{d}}}{\mathrm{mmol}}$} & \multirow{2}{*}{$\frac{\mathrm{CH}_{2} \mathrm{Cl}_{2}}{\mathrm{ml}}$} & \\
\hline & $\bar{M}_{n}$ & g & & & & & \\
\hline$A-1^{f}$ & \multirow{3}{*}{2200} & 7.5 & 32.0 & 64.0 & - & 40.0 & 10 \\
\hline$A-2^{g}$ & & 6.0 & 6.0 & - & 12.0 & 40.0 & 86 \\
\hline A-3 & & 6.0 & 6.0 & 12.0 & 6.0 & 40.0 & 89 \\
\hline B-1 & \multirow{4}{*}{3600} & 5.0 & 2.8 & - & 5.6 & 30.0 & 90 \\
\hline B-2 & & 2.5 & 2.1 & 4.2 & 2.1 & 20.0 & 97 \\
\hline B-3 & & 10.0 & 5.8 & 11.6 & 5.8 & 40.0 & 93 \\
\hline--- & & -- & & -- & 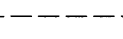 & -- & $--\cdots---$ \\
\hline C-1 & \multirow{2}{*}{6800} & 10.0 & 2.9 & - & 5.8 & 40.0 & 93 \\
\hline $\mathrm{C}-2$ & & 10.0 & 2.9 & 5.8 & 2.9 & 40.0 & 91 \\
\hline
\end{tabular}

a $t=22 \mathrm{~h} ; T=20^{\circ} \mathrm{C} . \quad{ }^{b}$ Tosyl chloride. $\quad$ c Triethylamine.

d 4-Dimethylaminopyridine. ${ }^{e}$ Determined by ${ }^{1} \mathrm{H}$ NMR spectrum.

${ }^{\text {f }} t=48 \mathrm{~h} ; T=25^{\circ} \mathrm{C}$. ${ }^{\text {g }} t=20 \mathrm{~h} ; T=20^{\circ} \mathrm{C}$. 


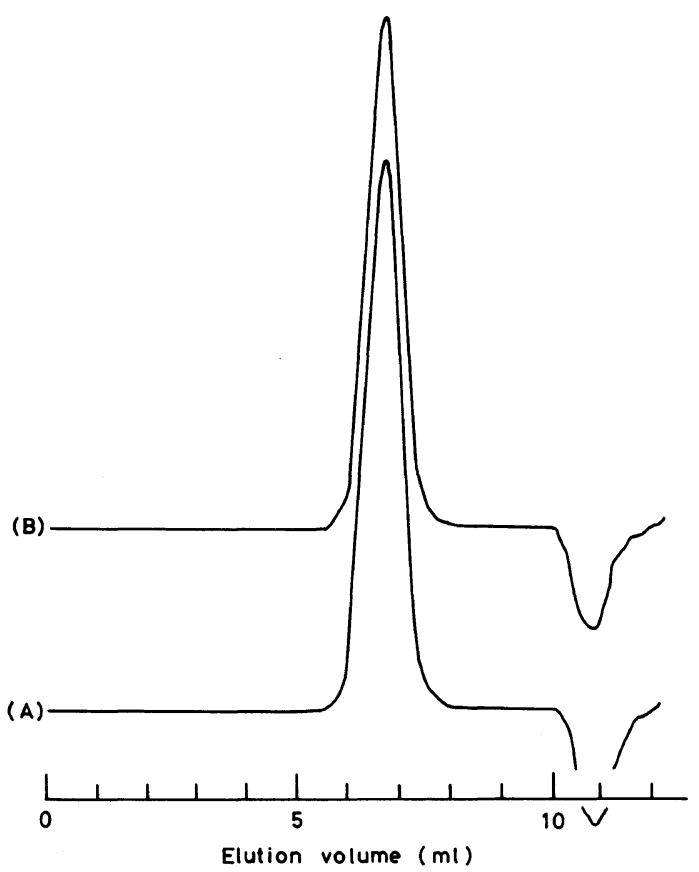

Figure 3. GPC trace of (A) poly(DMS) with silane end group (3) (No. 3 in Table I) and of (B) poly(DMS) with tosylated end group (5) (No. B-3 in Table III) (eluent, THF, $1.0 \mathrm{ml} \mathrm{min}^{-1}$ ).
$270 \mathrm{MHz}{ }^{1} \mathrm{H}$ NMR with the consumption of the hydroxypropyl end group.

During a series of modification and derivatization procedures of the end-standing functional group, the poly(DMS) oligomers retained its narrow molecular weight distribution intact as shown in Figure 3, where GPC traces of poly(DMS) with the tosylate end group (5) together with that of the starting poly(DMS) with silane end group (3) were present.

\section{Reactions of the Uniform Size Poly(DMS)} with Tosylate End Group (5)

The poly(DMS) with tosylate end group (5) thus obtained was utilized as a macromolecular initiator for the synthesis of a block copolymer through the nucleophilic reaction toward the tosylate ester function at the chain end by a monomer. Thus the reaction of the poly(DMS) having the tosylate end group with a nucleophilic monomer, namely 2-methyl-2oxazoline (OXZ) (6) was carried out to produce the hydrophobic-hydrophilic, poly-

Table IV. Results of the synthesis of poly(DMS)/poly(OXZ) block copolymer (7)

\begin{tabular}{|c|c|c|c|c|c|c|c|c|c|c|c|}
\hline \multirow{3}{*}{ No. } & \multicolumn{5}{|c|}{ Feed } & \multirow{3}{*}{$\frac{\text { Temp }}{{ }^{\circ} \mathrm{C}}$} & \multirow{3}{*}{$\frac{\text { Time }}{h}$} & \multirow{3}{*}{$\frac{\text { Yield }}{\mathrm{g}}$} & \multirow{3}{*}{$\begin{array}{c}\begin{array}{c}\text { OXZ content } \\
\text { in block } \\
\text { copolymer }\end{array} \\
\frac{\mathrm{wt} \%}{\mathrm{c} \%}\end{array}$} & \multirow{3}{*}{$\begin{array}{c}\begin{array}{c}\text { Conv. of } \\
\text { OXZ }^{d}\end{array} \\
\frac{\%}{\%}\end{array}$} & \multirow{3}{*}{$\begin{array}{c}\begin{array}{c}\text { Apparent } \\
\text { initiator } \\
\text { efficiency }\end{array} \\
\%\end{array}$} \\
\hline & \multicolumn{2}{|c|}{5} & \multirow{2}{*}{$\frac{\mathrm{OXZ}^{\mathrm{a}}}{\mathrm{g}}$} & \multirow{2}{*}{$\frac{\mathrm{Ph}-\mathrm{NO}_{2}{ }^{\mathrm{b}}}{\mathrm{ml}}$} & \multirow{2}{*}{$\frac{\text { Toluene }}{\mathrm{ml}}$} & & & & & & \\
\hline & $\bar{M}_{n}$ & $\mathrm{~g}$ & & & & & & & & & \\
\hline \multicolumn{2}{|c|}{ EtOTs } & 0.06 & 2.6 & 10.0 & 20.0 & 100 & 24 & 1.9 & - & - & - \\
\hline A-1 & \multirow{2}{*}{2200} & 1.3 & 1.5 & 10.0 & 20.0 & 80 & 48 & 1.3 & 77 & 67 & 23 \\
\hline A-2 & & 1.0 & 1.2 & 10.0 & 20.0 & 100 & 24 & 1.3 & 71 & 78 & 37 \\
\hline B-1 & \multirow{3}{*}{3600} & 3.0 & 6.4 & 15.0 & 30.0 & 80 & 38 & 4.9 & 77 & 59 & 37 \\
\hline B-2 & & 1.0 & 1.3 & 10.0 & 20.0 & 80 & 24 & 1.0 & 70 & 54 & 30 \\
\hline B-3 & & 1.0 & 1.3 & 10.0 & 20.0 & 100 & 24 & 1.1 & 77 & 66 & 25 \\
\hline C-1 & \multirow{2}{*}{6800} & 1.0 & 1.2 & 10.0 & 20.0 & 100 & 24 & 1.0 & 70 & 58 & 30 \\
\hline C-2 & & 1.0 & 1.2 & 15.0 & 15.0 & 100 & 24 & 1.6 & 63 & 84 & 59 \\
\hline
\end{tabular}

a 2-Methyl-2-oxazoline. ${ }^{\text {b }}$ Nitrobenzene. ${ }^{c}$ Determined by ${ }^{1} \mathrm{H}$ NMR spectrum.

d Conversion of $\mathrm{OXZ}=\frac{(\text { Yield }) \cdot(\mathrm{OXZ} \text { content in block copolymer sample })}{\mathrm{OXZ} \text { feed }}$. See also text.

e Apparent initiator efficiency $=\frac{(\text { Yield }) \cdot(\text { DMS content in block copolymer sample })}{\text { poly }(\mathrm{DMS}) \text { feed }}$. 

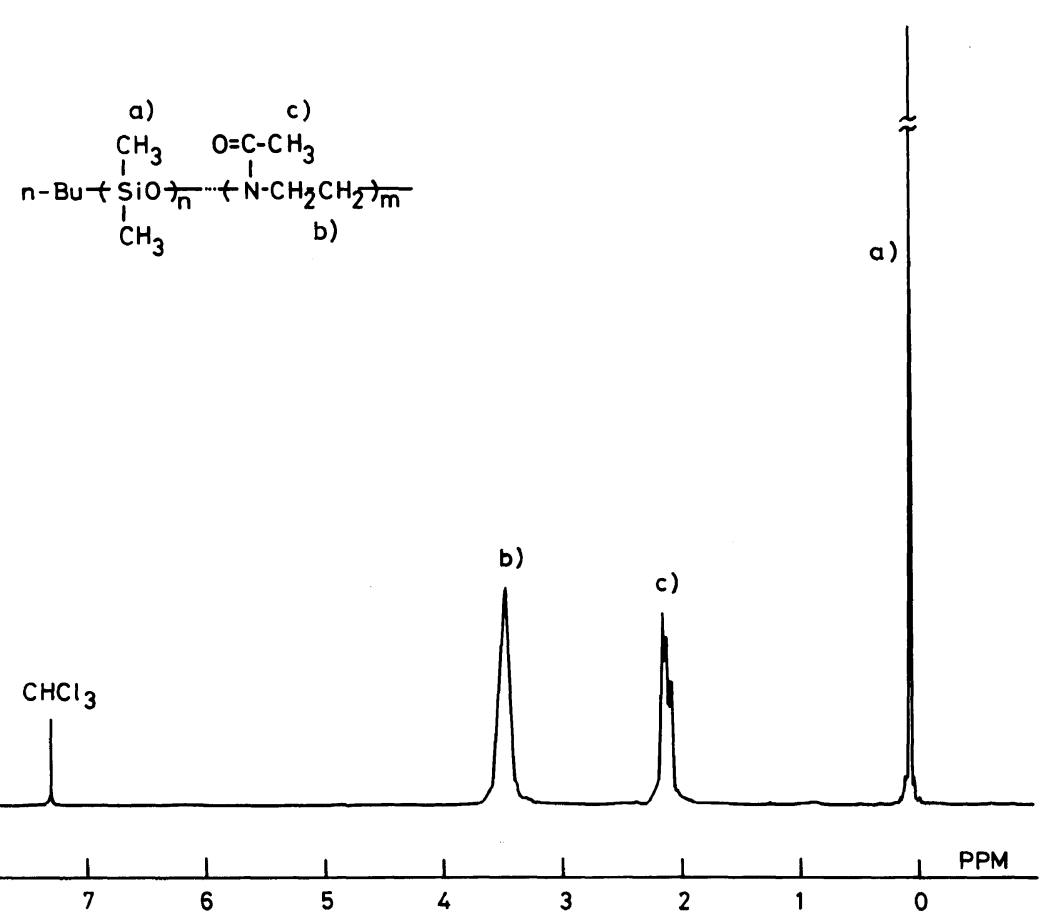

Figure 4. $270 \mathrm{MHz}^{1} \mathrm{H}$ NMR spectrum of poly(DMS)/poly(OXZ) block copolymer (7) (No. B-3 in Table IV) in $\mathrm{CDCl}_{3}$.

(DMS)/poly(OXZ) block copolymer (7), since the sulfonate ester can initiate the ringopening polymerization of oxazolines. ${ }^{13-15}$

The block copolymerization of $\mathrm{OXZ}$ was found to proceed in toluene/nitrobenzene mixture at either 80 or $100^{\circ} \mathrm{C}$, as summarized in Table IV. The reaction product was then analyzed by ${ }^{1} \mathrm{H}$ NMR, GPC, and TLC technique.

Figure 4 shows the $270 \mathrm{MHz}{ }^{1} \mathrm{H}$ NMR spectrum of the obtained poly(DMS)/ poly(OXZ) block copolymer (7). The presence of the overlapping signals due to both poly(DMS) and poly(OXZ) sequence indicates the formation of a block copolymer consisting of both segments.

The formation of the poly(DMS)/poly(OXZ) block copolymer (7) was also confirmed by the shift of GPC trace toward the higher molecular weight region for the block copolymer sample compared to that for the starting poly(DMS) with tosylate end group (5). (Figure 5) Nevertheless, the broadening of
Table V. TLC ${ }^{a}$ analysis of poly(DMS)/poly(OXZ) block copolymer (7)

\begin{tabular}{lcc}
\hline & \multicolumn{2}{c}{$R_{\mathrm{f}}$} \\
\cline { 2 - 3 } Polymer sample & In $n$-hexane & $\begin{array}{c}\text { In methanol/ } \\
\text { water }^{\mathbf{b}}\end{array}$ \\
\hline Poly(DMS) & 1 & 0 \\
Poly(OXZ) & 0 & $\doteqdot 1$ \\
Block copolymer (7) & 0 & 0 , and $\doteqdot 1^{\mathrm{d}}$ \\
\hline
\end{tabular}

a Aluminumoxide. b Vol. ratio 1:9.

c Table 4, No. B-1. d Two spots.

the molecular weight distribution accompanied by the lower molecular weight region was observed for the resulting block copolymer sample. This might be ascribed to the chain transfer reaction in the polymerization of OXZ (6) by the tosylate ester end group of poly(DMS). This chain transfer reaction, which is considered to produce poly(OXZ) homopolymer together with the block copoly- 


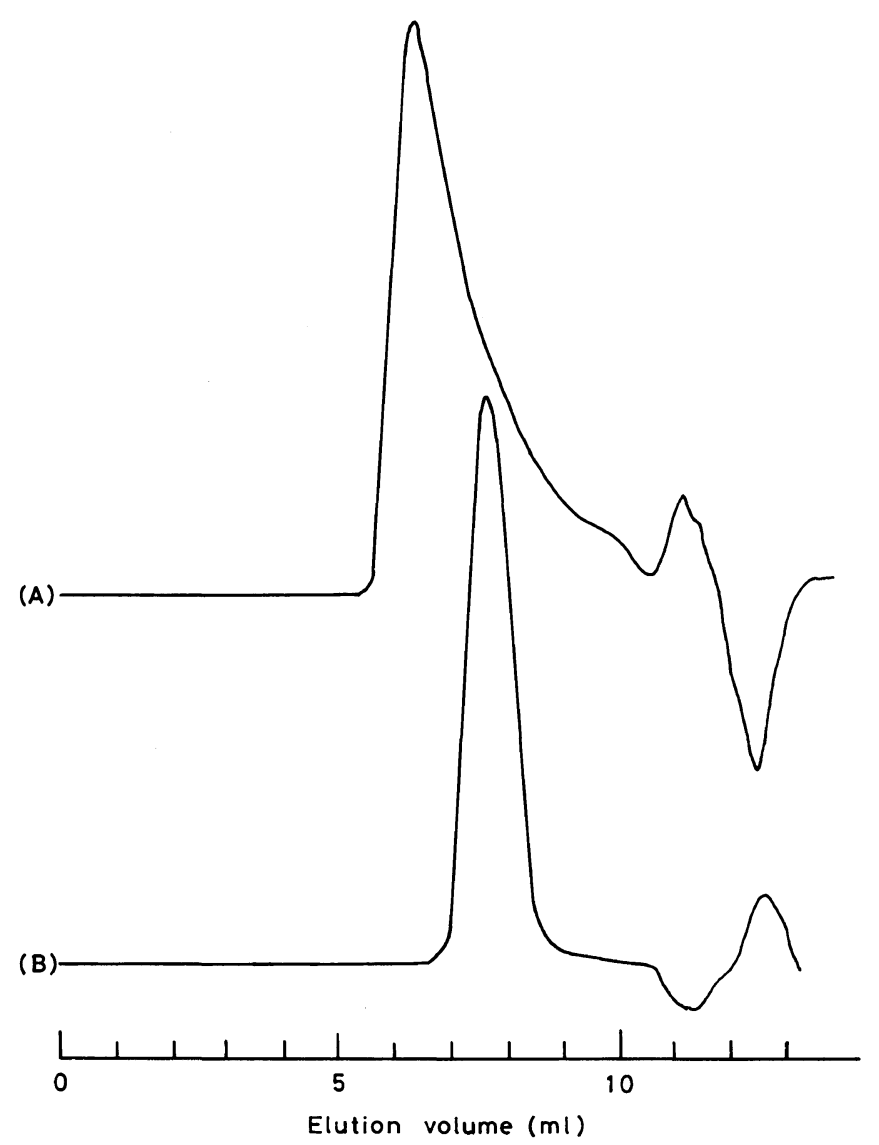

Figure 5. GPC trace of (A) poly(DMS)/poly(OXZ) block copolymer (7) (No. A-2 in Table IV) and of (B)

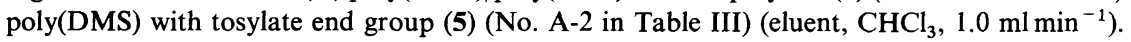

mer, was confirmed by TLC analysis of the block copolymer samples. As summarized in Table V, the poly(DMS) homopolymer was developed by a good solvent, $n$-hexane, but remained at the starting point due to the poor solvent, methanol/water (vol. ratio 1:9) mixture, whereas poly $(\mathrm{OXZ})$ showed opposite behavior due to its solubility toward the respective solvent. The examined block copolymer sample exhibited a minor spot assigned to the poly $(\mathrm{OXZ})$ homopolymer together with a major spot at the starting point due to the block copolymer component. An attempt to separate the minor portion of poly $(\mathrm{OXZ})$ homopolymer from the block copolymer sample by the usual reprecipitation technique was not successful due to the surface active nature of the block copolymer.

The poly(DMS)/poly(OXZ) block copolymer with a relatively short poly(OXZ) segment, thus produced in this chain transfer reaction, was found to be washed out together with poly(DMS) homopolymer during the purification procedures, which was confirmed from IR analysis of the wash out residue, showing characteristic absorption for poly(OXZ) segment. Consequently, the apparent low initiator efficiency given in Table IV is ascribed to the slow initiation process in OXZ polymerization by tosylate esters ${ }^{16}$ and also to the loss of a portion of poly(DMS)/ poly $(\mathrm{OXZ})$ block copolymer during the purifi- 
cation procedures.

The poly(DMS)/poly(OXZ) block copolymers (7) obtained in the present study were found to be surface active as expected and able to emulsify the water $/ n$-hexane mixture quite effectively.

Acknowledgment. The gift of $\mathrm{D}_{3}$ and dimethylchlorosilane from Toshiba Silicone Co. is gratefully acknowledged.

\section{REFERENCES}

1. S. L. Aggarwal, Ed., "Block Polymers," Plenum Press, New York, N. Y., 1970.

2. A. Noshay and J. E. McGrath, "Block Copolymers: Overview and Critical Survey," Academic Press, New York, N. Y., 1977.

3. I. Yilgor, A. K. Shaaban, W. P. Steckle, Jr., D. Tyagi, G. L. Wilkes, and J. E. McGrath, Polymer, 25, 1800 (1984) and references cited therein.

4. H. Gilman and A. H. Haubein, J. Am. Chem. Soc.,
66, 1515 (1944).

5. Y. Tezuka, A. Fukushima, and K. Imai, Makromol. Chem., 186, 685 (1985).

6. E. E. Bostick, Polym. Prepr., Am. Chem. Soc.; Div. Polym. Chem., 10(2), 877 (1969).

7. Y. Kawakami, Y. Miki, T. Tsuda, R. A. N. Murthy, and Y. Yamashita, Polym. J., 14, 913 (1982).

8. G. G. Cameron and M. S. Chishalm, Polymer, 26, 437 (1985).

9. J. L. Speier, R. Zimmerman, and J. Webster, J. Am. Chem. Soc., 78, 2278 (1956).

10. J. L. Speier, J. A. Webster, and G. H. Bames, J. Am. Chem. Soc., 79, 974 (1957).

11. P. Chaumont, G. Beinert, J. Herz, and P. Rempp, Polymer, 22, 663 (1981).

12. R. J. De. Vos and E. J. Goethals, Makromol. Chem., Rapid Commun., 6, 53 (1985).

13. A. Levy and M. Litt, J. Polym. Sci., A-1, 6, 57 (1968).

14. T. Saegusa and H. Ikeda, Makromolecules, 6, 805 (1973).

15. K. Ishizu, S. Ishikawa, and T. Fukutomi, J. Polym. Sci., Polym. Chem. Ed., 23, 445 (1985).

16. T. Saegusa, H. Ikeda, and H. Fujii, Macromolecules, 5, 359 (1972). 